\title{
Psychosomatic subjects and the agencies of addiction
}

\author{
Darin Weinberg
}

\section{Correspondence to}

Dr Darin Weinberg, Department

of Sociology, University of

Cambridge, Cambridge CB2

1TN, UK; dtw23@cam.ac.uk

Accepted 28 November 2018

Check for updates

(c) Author(s) (or their employer(s)) 2018. No commercial re-use. See rights and permissions. Published by BMJ.

To cite: Weinberg $D$. Med Humanit Epub ahead of print: [please include Day Month Year]. doi:10.1136/ medhum-2018-011582

\section{ABSTRACT}

Addiction science and public policy have for some time been articulated in conformity with a broader antinomy in Western thought between biological reductionism and liberal voluntarism. Hence, mainstream debates have concerned whether and how addiction might be understood as a disease in the biomedically orthodox sense of anatomical or physiological pathology or whether and how addiction might be understood as a voluntary choice of some kind. The fact that those who staff these debates have appeared either unable or unwilling to consider alternatives to this antinomy has resulted in a rather unhappy and intransigent set of intellectual anomalies both on the biomedical and the social scientific sides of this divide. Perhaps more importantly, it has also resulted in a striking isolation of scientific debates themselves from the vicissitudes of therapeutically caring for those putatively suffering from addictions both within and outside clinical settings. After briefly demonstrating the conformity of debates in addiction science with the broader antinomy between biological reductionism and liberal voluntarism and the anomalies that thereby result, this article considers the scientific and therapeutic benefits of a psychosomatic framework for the understanding of both self-governing subjects and the experience of a loss of self-control to agencies of addiction.

Addiction science and public policy have for some time been articulated largely in conformity with a broader antinomy in Western thought between biomechanical ${ }^{i}$ reductionism and liberal voluntarism. Hence, mainstream debates have concerned whether and how addiction might be understood as a disease in the biomedically orthodox sense of anatomical or physiological pathology or whether and how addiction might be understood as a voluntary choice of some kind. ${ }^{1-3}$ The fact that those who staff these debates have appeared either unable or unwilling to consider alternatives to this antinomy has resulted in a rather unhappy and intransigent set of intellectual anomalies both on the medical and the social scientific sides of this divide. In this article I focus primarily on their failure to provide adequately for the agency of addictions in contrast to the agency of those who suffer

${ }^{\mathrm{i}}$ The term biomechanical is used here to highlight the contrast between biological and voluntaristic theories of addiction. Whereas biology subscribes to a natural scientific conception of the world as invariably governed by natural laws and/or mechanisms, voluntaristic theories like those found in economics and other social sciences subscribe to the view that human choices are not predetermined by, or reducible to, natural laws or mechanisms but rather are in some sense freely adopted. from them. Perhaps more important than its intellectual failings, this antinomy has also resulted in a rather striking isolation of scientific debates themselves from the vicissitudes of therapeutically caring for those putatively suffering from addictions both in and outside clinical settings. After briefly demonstrating the longtime conformity of mainstream debates in addiction science with the broader dichotomy between biological reductionism and liberal voluntarism and the anomalies that thereby result, the article considers the scientific and therapeutic benefits that follow from the adoption of a psychosomatic framework for the understanding of both free agency, or self-governing subjects, and the experience of a loss of self-control to agencies of addiction.

The definition and purview of psychosomatics is and has been variously formulated perhaps for as long as the term has been in use. My objective in this article, then, is not to decisively establish what psychosomatics is and then apply its principles to our understanding of free agency and the agency of addiction. Rather, I draw eclectically from authors who have articulated positions in keeping with the enduring psychosomatic impatience with dualisms between minds as sentient and purposeful moral agents and bodies as indifferent and amoral machines. Relatedly, I draw on critiques of mind/body dualists' widespread tendency to posit both minds and bodies as categorically distinct from one another and as invariably singular, integrated systems, the nature of which can be understood independently of the particular sociohistorical environments within which they emerge and are sustained. In so doing, I show how these broadly psychosomatic insights allow us to better understand the difference between free agency and the agency of addiction. And, more importantly, they allow us to more effectively both warrant and facilitate therapeutic care for people suffering from addictions.

\section{ADDICTION AS MEDICAL DISEASE}

Since the earliest days of its medicalisation, addiction has been typically characterised as in some sense a biological affliction of the will. ${ }^{4-10}$ In the first decade of the 19th century, Benjamin Rush's pamphlet, An Inquiry into the Effects of Ardent Spirits Upon the Human Body and Mind, asserted that habitual drunkenness is indeed a medical disease. ${ }^{11 \mathrm{ii}}$ And in Medical Inquiries and Observations upon Diseases of the Mind, Rush wrote, 'The use of strong drink is at first the effect of free agency. From habit it takes place from necessity'. ${ }^{12}$

${ }^{i i}$ Earlier editions of this pamphlet, first published in 1784 as An Inquiry into the Effects of Spirituous Liquors on the Human Body, made no reference to habitual drunkenness as itself a disease but confined attention to its role in causing other diseases. 
It was on this basis that in his landmark study 'The Discovery of Addiction', Levine ${ }^{4}$ held that Rush's writings marked a watershed where earlier religious orientations to habitual drunkenness as a sinful free choice were overtaken by a medical one stressing a supplanting of the addict's 'free agency' by a pathological condition.

While the specifics of Rush's writings on addiction have not survived the test of time, it has remained a core objective of addiction medicine to distinguish the agency of addictions from the otherwise 'free agency' of those who suffer from them. Most prominent among the motivations driving this core objective has been a desire to mitigate the blaming of addicts for the moral failures linked to their addictive behaviours. ${ }^{13} 14$ In many versions of this perspective, the agency of addiction has been located in the objects of addiction themselves. Hence, for example, even today one often reads of the intrinsically addictive powers of drugs like alcohol, heroin, cocaine, nicotine or fentanyl. Although widely accepted as an article of common sense both among health professionals and the public alike, the preponderance of scientific evidence runs counter to these theories. The difficulty with locating the agency of addiction in the objects of addiction themselves has been that these objects appear to be addictive to only a small minority of those exposed to them. Epidemiological studies routinely show that most of those who ingest the so-called addictive substances never fall into harmful patterns of use, let alone lose control. ${ }^{3}{ }^{15}$ Accordingly, mainstream addiction medicine has sought to locate the agency of addiction through anatomical and physiological investigations of the bodies of those presumed afflicted. This said, there has nonetheless persisted, even among biomedical experts, a curiously obstinate tendency to blame addicts for their condition. As will be seen, this tendency to blur the line between the medical and moral gaze, while perhaps mysterious by the lights of an orthodox biomechanical reductionism, is easily explained from a psychosomatic perspective.

Thought they cannot be said to have captured the imaginations of most mainstream medical doctors, the 19th century saw a fairly diverse proliferation of medical theories of addiction. Most drifted from a direct concern with the biological agency or agencies compelling involuntary drug consumption to topics like delirium tremens and other acute effects of alcohol in the body, topics of little relevance to the clinical management of self-destructive drug habits but more easily brought to heel by the experimental and conceptual resources available to medical science. Among the most influential 19th-century theories were degeneracy and neurasthenia. Following the French psychiatrist Benedict Augustin Morel, many attributed addictions to degenerate hereditary predispositions. While fundamentally physical in nature, these predispositions were said to compromise moral and mental fitness, rendering those afflicted permanently prone to addiction. The theory of neurasthenia, promoted most prominently by the American neurologist Charles Miller Beard, held that modern civilisation neurologically overstimulated those of more refined sensibilities. This, in turn, rendered them vulnerable to a range of infirmities including addiction. Similar to degeneracy theory, neurasthenia located the agency of addiction in the addict's compromised biological constitution. But unlike the therapeutic pessimism of degeneracy theory, the theory of neurasthenia, by also pathologising modern civilisation, offered a therapeutic path forward in a period of regenerative asylum from the putative turmoil of urban industrial society. What must be noted in both cases, however, is their failure to distinguish addicts' free agency from the agency of their addiction. While biologically compromised and socially transgressive, it was not at all clear how the degenerate or neurasthenic could be held to have genuinely lost their free agency rather than merely exercising it deficiently.

As the 19th century came to a close, the public debate on addiction turned decidedly away from reforming or caring for those with addictions and towards prohibition. Addiction science, to the extent it survived, was engulfed by this more general cultural trend and was largely subordinated to criminal justice agendas. Accordingly, putative addicts were increasingly cast as incorrigible psychopaths or deranged skid row derelicts (in either case beyond hope of therapeutic reform) and, as was the case with degeneracy theory, their free agency was rendered indistinguishable from the agency of their addiction. As psychodynamic psychiatry gradually fell from favour in the medical community and public disenchantment with strictly criminal controls grew more pervasive, addiction medicine was increasingly drawn to focus on the development of drug tolerance and physiological withdrawal symptoms. ${ }^{16-18}$ By these lights, addicts were no longer seen as intrinsically inferior beings but, rather, physiologically 'hooked' or 'dependent' on drugs and compelled to stave off withdrawal through continued use. Although, in contrast to degeneracy and psychopathy, dependency theories did not disparage the addict's inherent rationality, it remains far from clear how withdrawal symptoms might be held to somehow displace the free agency of those who experience them rather than just changing and narrowing people's priorities. Mere dedication to the avoidance of withdrawal symptoms is a rather dubious stand-in for a genuine loss of one's free agency. Moreover, drugs like cocaine and nicotine and activities like sex, gambling, shopping, internet use and eating appear capable of arousing addictions as self-destructive as those involving alcohol and opiates without producing physiological withdrawal symptoms at all.

It is in part due to the accumulation of such anomalies along with new techniques of neurological investigation that over the last three decades interest has turned to the most recent paradigm in biomedical addiction science, the brain disease model of addiction. ${ }^{19-21}$ The brain disease literature accounts for what is often called the 'hijacking' of our free agency by the agency of addiction in two main ways. First, according to incentive sensitisation theory, the intensity of addicts' desire (want) for drugs is neurologically separated from the pleasure they derive from (like) drugs, seeming therefore to make the desire irrational and, by implication, unfree. ${ }^{22}$ But wanting something more than one likes it does not logically entail a displacement of free agency nor do people necessarily experience it as such-consider, for example, wants like exercise and a healthy diet. While we may want these things, it does not follow that if we do not like them as much as we want them we have therefore lost control of ourselves. Hence, like withdrawal theories, incentive sensitisation theory conspicuously fails to specify an agency of addiction that is distinguishable from addicts' otherwise free agency.

The second way brain disease theorists argue that addictions displace people's free agency is by compromising the brain's so-called executive functions. ${ }^{23}$ These functions cover things like attention, response inhibition, planning, problem solving and working memory. But insofar as they systematically ignore the actual, real-world, preferences of particular people, this research strays rather far from the lived realities and experiences of free agency and its loss in the real world. To claim that in real life people uniformly equate free choices with executive functions like long-term planning, problem solving and impulse control is empirically false. Not only do we freely throw caution to the wind on occasion but so too on occasion do we link our free 
choices with our gut instincts, spontaneous sensibilities or predilections, and indeed equate the kinds of activities associated with executive function with alienation from our real selves and authentic free agency. ${ }^{24-26}$ Indeed precisely because they hope to empower addicts by re-establishing their authentic sense of themselves, addiction rehabilitation programmes routinely place extensive therapeutic emphasis not on teaching people to executively inhibit their spontaneous sensibilities but on 'getting in touch' with them through their free and open expression. ${ }^{\text {iii }}$

In this brief summary of the history of addiction medicine, I have shown some of the main ways in which addiction has been construed in biomedical terms that despite their proponents' best efforts to do so nonetheless fail to either provide adequately for the epidemiological and clinical facts or for the agency of addiction specifically as something that compromises addicts' otherwise free agency. These failures have served to rather considerably distance biomedical addiction science from the lived experiences of addicts themselves and, relatedly, to seriously diminish the utility of biomedical addiction science to those who seek to clinically, or otherwise therapeutically, care for those suffering from addictions. ${ }^{20}$ In the next section I show how those who reject the disease model and seek instead to cast addictions as non-pathological, although self-destructive, patterns of free choice have also strayed rather considerably from the lived experiences of addicts and thereby compromised their own capacities to inform the work of therapeutic carers.

\section{ADDICTION AS CHOICE}

The medicalisation of addiction and its purported exoneration of putative addicts from moral responsibility has always been contested, often fiercely so. ${ }^{27-29}$ Indeed the idea that addicts never in fact lose their free agency remains widespread in both the social sciences and popular culture. Dating at least as far back as John Stuart Mill's essay 'On Liberty', ${ }^{30}$ this position has been based in large part on the normative propositions that all people are naturally endowed with the faculty of self-government and that it is unjust to suppress their free exercise thereof. ${ }^{31}{ }^{32}$ Perhaps ironically, these normative propositions have become widely entrenched in the social sciences via ostensibly value-neutral postures of agnosticism towards elite and/or mainstream norms disparaging historically marginalised and/or vilified groups and a concomitant emphasis of their local rationality and legitimacy. ${ }^{33-35}$ This has been part of a more general social scientific tendency to understand social reality as invariably composed of the consensual or conflictual interactions of a diversity of integrated social groups and to define their members as integrated individuals-rational, self-governing agents who affiliate with these groups based on their belief in the group's distinctive traditions, interests or values.

Hence, more specifically, by the mid-20th century putative addicts were routinely understood as members of subcultures with their own distinctive value systems rather than sufferers of intrinsic personal afflictions or deficits of any kind. Concerned

\footnotetext{
iii This tendency to equate free agency with response inhibition or impulse control and the loss of free agency with a submission to one's impulses is not confined to the brain disease model but can also be seen elsewhere as in the disinhibition literature ${ }^{68} 69$ and the literature on 'ego-depletion'. ${ }^{70}$ But there are no compelling theoretical or empirical reasons to generically, or universally, equate disinhibition with a loss of free agency either. People often very deliberately use alcohol or drugs to reduce their inhibitions without feeling, or inviting the accusation, that they have
} in any way forsaken their free agency or self-control. to avoid slipping from their presumed value neutrality into an illiberally biased moralism, social researchers have often overlooked the fact that addiction, understood specifically as a loss of self-control, is an idea putative addicts often themselves take seriously and which is not necessarily coercively imposed from without. Moreover, the comparatively few social scientific studies that do treat addiction as a cause of personal suffering tend to render it in ways that do not jibe well with much of the available evidence. ${ }^{3637}$ In short, social scientific studies have heavily tended to hold that addiction reflects a notorious but nonetheless conscious, deliberate, self-governed and, hence, voluntary choice to value the use of drugs over matters that others in society consider more important. ${ }^{38}$

Since roughly the 1980s, a growing collection of self-described 'choice theorists' in economics, social psychology, philosophy and even neuroscience itself has sought to more rigorously and methodically develop this position. These theorists tend to begin with the observation that most behaviours attributed to addictions are 'incentive sensitive' (at least partially consistent with cost-benefit analysis) and not compulsive in the orthodox neurological sense emphasised by disease theorists. While this is true, we should be careful not to make too much of it. Plants are incentive-sensitive in the sense that they grow towards resources like light and water, but we would not normally want to conceptualise this as a voluntary choice.

Most credit Becker and Murphy ${ }^{39}$ with launching this new line of research with their argument that addictions reflect deliberate choices made in full knowledge of their future costs and benefits and that addicts' preferences remain stable over time. Orphanides and Zervos ${ }^{40}$ criticised Becker and Murphy ${ }^{39}$ for casting addicts as without regret and, because they are already fully cognizant of the future costs and benefits of their choices, unentitled to (and without need for) therapeutic help. Orphanides and Zervos ${ }^{40}$ introduced the possibility of learning, regret and inadvertently falling into addiction, but did so by merely insisting on the addict's initial ignorance rather than considering the possibility that their preferences may in fact be incoherent or unstable. While hypothetically providing for its onset, their argument fails to provide for people's ongoing struggles with addiction or the fundamental warrant for, or logic of, specifically therapeutic interventions.

Most choice theorists have abandoned the effort to explain addiction by the lights of orthodox rational choice theory. ${ }^{1}$ For example, George Ainslie, and others, have influentially argued addicts are prone to prefer present to future rewards and to 'hyperbolically discount' the prospects of future costs and benefits. $^{2} 194142$ They thereby reject the postulate that people are fully future-oriented cost-benefit analysts in the sense demanded by orthodox rational choice theorists. The greater the expectation of immediate reward and the greater the expected intensity of that reward, the more we become vulnerable to temptations to abandon our longer term plans and preferences. While these kinds of modifications have increased the credibility of choice theoretic arguments, even modified arguments often remain tenuously grounded in empirical data and have been criticised for merely providing formal descriptions of idealised narratives of addiction rather than explaining actual empirical instances of it. ${ }^{43}$ Moreover, by closing the distance between addiction and generic features of human choice making, like our ubiquitous tendencies to hyperbolically discount future costs and benefits choice, theorists tend towards a normalisation of addictive reasoning and volition. This makes it difficult to see why or how addiction should warrant suspension of our default practices of holding ourselves and one another morally accountable for our 
actions in favour of a more therapeutic, sympathetic and exculpatory stance.

Therapeutic work does not in the first instance require theories that serve only to plausibly explain or justify putatively addicted behaviour; it specifically requires theories that allow these behaviours to be plausibly disowned. It is only by plausibly distinguishing the free agency of addicts from the effects of their addictions that people might be simultaneously understood as amenable to therapeutic empowerment or emancipation from their addictions and somehow also afflicted by an agency of addiction that justifies and demands such a therapeutic engagement in the first place. Furthermore, those struggling to overcome addictions require theories that go beyond merely providing credible justification for absolution, or the disowning of past misdeeds. As all who have sought to care for addicts know, recovery is an essentially ongoing exercise of learning to anticipate and prevent the rekindling of people's addictions, and it requires theories that not only facilitate, but actually warrant, such a project in the first place. ${ }^{44}$

Choice theorists have made little, if any, headway in this regard. Pickard, ${ }^{45}$ for example, offers the enticing possibility of holding addicts responsible for overcoming their addictions but not blaming them for their addictions. But this turns out to be a distinction not between addicts' responsible free agency (which it is the work of therapy to empower) and the agency of their addictions (which might be suppressed and blamed for anticipated relapses). It is a distinction between 'detached' and 'affective' blame. Detached blame is retained as both a basis for demanding behavioural change and for negatively sanctioning problematic behaviour. We must renounce only affectively infused spite in response to what Pickard ${ }^{45}$ calls the addict's 'disorder of choice'. Conspicuously missing from her account are (1) a warrant for the claim that addicts are emancipated rather than merely domesticated by the changes 'therapeutically' imposed on them through negative sanctioning, and (2) a warrant for viewing addicted choices as somehow 'disordered' rather than just blameworthy-that is, a warrant for therapy over criminal corrections or civil retribution. The British criminal justice system certainly blames criminals and is not primarily concerned to therapeutically care for them. But it does nonetheless seek to appear dispassionate in its dispensation of justice. Or in Pickard's ${ }^{45}$ language, to favour 'detached' over 'affective' blame, just deserts over lynch mobs.

Similarly, while vigorously and masterfully critiquing brain disease models for mistaking neurological markers of normal learning as markers of pathological brain damage, ${ }^{\text {iv }}$ Lewis ${ }^{46} 47$ repeatedly backslides from his addiction-reflects-normal-rather-than-pathological-learning-processes thesis into statements that addictive learning neurologically 'distorts' cognitive functioning. This lapse into usage of the negatively value-laden term 'distort' with its implications of disfigurement and perversion is plainly driven by a desire to provide warrant for therapeutic as opposed to coercive interventions. But he offers no explanation for why addiction should be understood as a 'distortion' of normal learning. Having denied himself access to the medical mantle of disease, Lewis ${ }^{46} 47$ cannot reconcile his belief that addicts should be cared for and not blamed with his belief that addictions are nonetheless patterns of choice and products of the positively value-laden term 'learning' with its implications of personal growth, skills or knowledge acquisition. In sum,

\footnotetext{
${ }^{\text {iv }}$ Lewis routinely equates the neurology of negatively valued drug addictions with positively valued preoccupations with things like romantic relationships, sports and summer holidays. ${ }^{71}$
}

addiction science and policy remains to this day torn between the Scylla of a biomechanical reductionism that cannot provide for the richly layered nuances of personal freedom as it is exhibited in contemporary societies and the Charybdis of a liberal voluntarism that axiomatically forecloses on explaining the lived experiences of unfreedom that appear to sometimes flow from intrapersonal clashes among what Mills $^{48}$ called our myriad 'tastes and pursuits'.

\section{PSYCHOSOMATIC SUBJECTS AND THE AGENCIES OF ADDICTION}

The definition and purview of psychosomatics is and has been variously formulated perhaps for as long as the term has been in use. ${ }^{49}$ My objective in this section, then, is not to decisively establish what psychosomatics is and then apply its principles to our understanding of free agency and the agency of addiction. Rather, I draw eclectically from authors who have articulated positions in keeping with the enduring psychosomatic impatience with dualisms between minds as sentient and purposeful moral agents and bodies as indifferent and amoral machines. ${ }^{50}$ Relatedly, I draw on critiques of mind/body dualists' widespread tendency to posit both minds and bodies as distinct from one another and as invariably singular, integrated systems, the nature of which can be understood independently of the particular sociohistorical environments within which they emerge and are sustained. In so doing, I show how these broadly psychosomatic insights allow us to better understand the difference between free agency and the agency of addiction. And, perhaps more importantly, effectively both warrant and facilitate therapeutic care for people suffering from addictions.

Here is not the place to rehearse the diverse critiques that have been lodged against Cartesian dualism. From Marx, to American pragmatism, to Heidegger, Merleau-Ponty and existential phenomenology, a growing collection of researchers have argued respectively for an embodied understanding of our minds' activities and mindful understanding of our bodies' activities. In a particularly incisive study of the 'odour kits', perfume makers use to train 'noses' to detect progressively subtler aromatic contrasts, Latour ${ }^{51}$ makes a strong empirical case for such a psychosomatic subjectivity. In this study Latour ${ }^{51}$ demonstrates the body is not just an objective biomechanical system about which we can subjectively learn but, fundamentally, a mutable medium literally 'articulated' through its 'learn[ing] to be affected'. Latour ${ }^{51}$ goes a considerable distance towards creating a conceptual space within which addiction might be construed as an acquired but nonetheless eminently embodied form of subjectivity. By retaining a focus on the subjective, or lived sentient, body he accommodates much of what choice theorists seek to achieve by emphasising incentive sensitivity, neuroplasticity and by narrowing the distance between addiction and normal learning processes. But although he speaks of the multiplicity of environments within which the body subjectively learns to be affected, Latour ${ }^{51}$ does not address the multiplicity of the body itself-as not just an articulated medium for learning to be affected but a linked set of media for doing so. This limits his sensitivity to the potentials for embodied conflicts and/or afflictions like addiction.

The tendency to think of subjectivities, minds and/or bodies as singular and unified is also hegemonic throughout the mainstream addiction science literature on both the disease and choice sides of the debates. However, research in neurology, psychology and sociology is itself now beginning to discover the reality of disunity. For example, Lewis has written in this regard that habit learning originates piecemeal in setting specific kinds of ways 
but that eventually, because brains tend to conserve structure and resources, habits, or acquired 'synaptic networks,' often converge and become mutually reinforcing. Crucially, however, he notes these processes need not converge on a wholly unified subject, or fully integrated hub for all experience, deliberation and volition. Instead, 'alternative synaptic networks can compete with each other...this is the case when addiction arises in development, but also when it dissipates, replaced by the desire for and belief in alternative outcomes'. ${ }^{52}$ What Lewis fails to fully appreciate, however, and what prevents him from reconciling his incisive understanding of the neurology of addiction with his hope to produce a warrant for therapeutic care is the labile and dynamic relationships that occur between the diverse psychosomatically embodied subjectivities he describes as the neuroplastic synaptic networks that comprise our biomechanical brains on the one hand, and on the other hand our selves specifically as morally accountable subjects.

Lewis, ${ }^{19}$ like most addiction scientists, argues that addiction is a constellation of habits that grow from the repeated pursuit of something highly desired. But his distinctive emphasis on neuroplasticity and the disunity of our synaptic networks opens an unprecedented path towards a more psychosomatic understanding of both free agency and the agency of addiction. While he acknowledges a deep intellectual debt to Kent Berridge, ${ }^{53}$ who has argued that some substances and/or experiences are naturally or intrinsically desirable given the neurological hardwiring of our brains, Lewis never himself explicitly adopts this view and is, as noted, much more likely to highlight neuroplasticity and neurodiversity than hardwired universal dispositions. Unlike most neurologists, then, his work is consistent with the phenomenological fact that not all people enjoy drug-induced experiences. It is also consistent with the fact that particular people may enjoy these experiences under some circumstances and wholly detest them under other circumstances (an example I often give with students is to contrast the experience of being drunk at a party to the experience of being drunk in a final exam). These facts combined with Lewis' insights into the neuroplastic and neurodiverse causes of desire strongly support a view of the body as host to psychosomatically diverse desiring subjectivities. And, conversely, they also cast considerable doubt on the prospects of ever fully reducing subjective and particular experiences of pleasure, pleasure seeking, pain or pain avoidance to the generic functions or dysfunctions of generic neurological structures. However, an intriguing and promising compliment to research on the neuroplastic and neurodiverse origins of desire can be found in the traditions of psychoanalytic and phenomenological thought that have sought to develop non-reductionist and more dynamic understandings of the human libido.

\section{Merleau-Ponty, ${ }^{54}$ for example, writes:}

For Freud himself, the sexual is not the genital, sexual life is not a mere effect of the processes having their seat in the genital organs, libido is not an instinct, that is, an activity naturally directed towards definitive ends, it is the general power, which the psychosomatic subject enjoys, of taking root in different settings, of establishing himself [sic] through different experiences, of gaining structures of conduct.

Here Merleau-Ponty ${ }^{54}$ suggests a radical departure from a view of the psychosomatic subject as a unified desiring agent and poses the possibility of conceiving pleasures and desires as being diversely forged 'in different settings'. A critic of the transcendental ambitions of phenomenologists like Husserl, Merleau-Ponty ${ }^{54}$ casts the first-person experience of the lived body, including its pleasures and desires, as always an occasioned, situated and provisional affair rather than a neurological, psychoanalytic or phenomenological fait accompli. Similarly, while casting our experiences of the lived body as inherently diverse, elusive and ambiguous, he studiously avoids invoking an unconscious mind comparatively insulated from the body or the myriad practical conditions within which we find ourselves. Instead, Merleau-Ponty ${ }^{54}$ takes a more praxiological stance, holding that conscious experience is always shaped by the various ways we are practically engaged with and immersed in worlds at a preconscious or habitual level. Embodied, preconscious or habitual coping, then, is prior to conscious interpretation-or, indeed, the conscious identification of any 'thing', including our own 'self'.

These ideas, including that of a praxiologically disaggregated libido, directly influenced Bourdieu ${ }^{55}$ in his formulations of the habitus. However, like Latour's model of bodily articulation, Bourdieu $^{56}$ also sometimes casts the habitus as a unified set of dispositions or 'unifying principle which retranslates the intrinsic and relational characteristics of a position into a unitary lifestyle, that is, a unitary set of choices, persons, goods and practices. This said, very good reasons can be found both in Bourdieu's own work and elsewhere to suggest a more fragmented or pluralised habitus, ${ }^{57}$ one that allows comparatively greater emphasis on the relationships between particular praxiological fields and the respective habitus forged therein rather than the developmental sedimentation emphasised in his more unitary accounts. For example, Bourdieu's protégé, Loic Wacquant,${ }^{58}$ writes in this regard:

habitus is not necessarily coherent and unified. Rather, it displays varying degrees of integration and tension, depending on the character and compatibility of the social situations that fashioned it over time. A sequence of congruent institutions and stable microcosms will tend to fashion a cohesive habitus whose successive layers reinforce one another and work in unison. Dissimilar organizations anchored by divergent values or entropic universes, by contrast, cultivate unstable systems of dispositions divided against themselves and wont to generate irregular and inconsistent lines of action.

This suggests an image of psychosomatic subjects as to varying degrees either integrated or disintegrated depending on the empirical conditions under which they have been fashioned. Wacquant's ${ }^{58}$ invocation of 'unstable systems of dispositions divided against themselves and wont to generate irregular and inconsistent lines of action' will no doubt ring a bell for students of addiction. The fact that these dispositions are understood as acquired but preconscious or habitual is also deeply resonant with what we know empirically about addictions. But the most potentially groundbreaking advantage of this approach is its positing of what might be called an ecological ${ }^{v}$ axis for considering how systems of dispositions might become divided against themselves. This ecological emphasis better accounts than does

\footnotetext{
'The term 'ecological' is used here for two reasons. First, it connotes the materiality of an environment more than do terms like 'culture', 'context' or 'social space', which are sometimes held to refer only to 'webs of significance' or symbolic environments. ${ }^{72}$ Second, and more importantly, the term 'ecology' indicates a reciprocal relation between agent and environment without presuming the humanity of the agent in question. Insofar as I am distinguishing agencies of addiction from the human agents said to suffer from them, it is useful to avoid anthropomorphic terms when describing the environments within which addictions are held to be forged, kindled and rekindled.
} 
ascendant addiction science for the widespread observation that most addicts 'mature out' of addiction as their life circumstances change. ${ }^{59}$ It also better provides for Robins ${ }^{60}$ findings of minimal relapse to heroin use among returning Vietnam veterans; Waldorf' $\mathrm{s}^{61}$ and Biernacki ${ }^{62}$ findings of a commonly experienced association of recovery from addiction with removal from the types of settings and associates that had constituted one's practical contexts of drug use; and the widely recognised recovery advantage had by addicts with comparatively wider ranges of coping skills and what Waldorf et al ${ }^{63}$ call a 'stake in conventional life'. These studies strongly suggest addiction is often a more or less context-specific form of bodily articulation and that the experience of a loss of self-control is caused not only by the biomechanical relationship between user and drug but by conflicts among the various ecologies, the specific constellations of practical and relational contexts, one has come to inhabit and within which one feels compelled to live.

Still more importantly, pertaining to the warrant and facilitation of therapeutic care for addicts, this approach valuably augments what is now a virtually unrivalled understanding of the instability of addicts' dispositions to act in terms of a temporal contrast between short-term and long-term preferences. ${ }^{2} 1964$ Despite their earnest hopes to encourage compassion and therapeutic care, the steadfast, almost myopic, focus of addiction scientists on temporal mechanisms of preference instability like incentive sensitisation and hyperbolic discounting inevitably results in images of addicts as impulsive, hedonistic, shortsighted, undisciplined and incapable of deferring gratification. Weighed down by images like these, it is very difficult to counter the ubiquitous tendency both among healthcare professionals and the wider public to blame addicts for their fates.

The approach proposed here allows for an entirely different take on addicts' unstable dispositions-one that posits a clash of ecologically grounded psychosomatic subjectivities rather than a clash of short-term and long-term preferences. While we are all prone to greater and lesser degrees of psychosomatic integration depending on the extent to which we have been shaped by what Wacquant above calls '[d]issimilar organizations anchored by divergent values or entropic universes', the failure of integration can sometimes become so extreme as to precipitate a radical disowning of particular psychosomatic subjectivities—a radical personal and moral divestment from those subjectivities that effectively divorces certain constellations of entrenched habit from our own or our significant others' sense of who we really are-that is, the agency of our addictions from our free agency specifically as self-discovering, self-actualising and self-governing moral subjects.

\section{CONCLUDING REMARKS}

Neither performance-enhancing nor dysfunctional drug use can be adequately understood in artificial isolation from the specific assemblages of ecological—practical and relational—contexts within which pleasure and pain, personal ease and dis-ease, competent and incompetent performance, receive their genuine measure. ${ }^{65-67}$ As argued above, the body is not a singular psychosomatic medium through which we learn to be affected, but a complex constellation of such media each shaped in the first instance by the various ecological environments within which we learn to effectively and affectively conduct our lives. The assorted articulations of our bodies having learnt to be affected will inevitably differ in the extent to which they are deemed productive or satisfying, unproductive or unsatisfying by ourselves and those with whom we share our lives. These assessments will largely dictate whether, and the comparative extent to which, we self-identify with our body's different articulations and the comparative extent to which our significant others identify us with some rather than others.

Seen in this light, the status of addiction as a form of disease need not be decided with rigid reference to whether suffering can be decisively linked to isolated dysfunctional biological mechanisms, but, more generally, with reference to any number of different patterns of seemingly harmful, alienating and intransigent bodily articulation. That is, patterns of ecologically grounded psychosomatic subjectivity with which we cannot, or do not want to, identify our selves precisely because they appear to afflict or endanger those of our psychosomatic subjectivities with which we do self-identify. This understanding of the relationship between free agency and the agencies of addiction also illuminates better than does received addiction science why and how interventions like 12 -step groups and therapeutic communities of various stripes have been so comparatively attractive to those seeking therapeutic help with their addictions and to those predisposed to provide such help. In contrast to other forms of therapeutic care, these kinds of interventions seek to emphasise the provision of immersive ecological alternatives to the spaces within which people's addictions were forged, and within which they might continue to be kindled and rekindled. They are, in other words, comparatively better keyed to the linkage of our various psychosomatic subjectivities to the various ecological spaces within which they are acquired and sustained and within which we also evaluate their compatibility with our specific projects of self-discovery and ongoing self-actualisation. Rather than focus, as most addiction science has, on therapeutic techniques for fostering people's commitment to longer term over shorter term cost-benefit calculations, ecologically grounded interventions direct considerably more attention to the details of the worlds within which our particular efforts to self-actualise (in both the shorter and the longer term) are most and least likely to be stabilised and to thrive.

Contributors There are no other contributors.

Funding The authors have not declared a specific grant for this research from any funding agency in the public, commercial or not-for-profit sectors.

Competing interests None declared.

Patient consent for publication Not required.

Provenance and peer review Not commissioned; externally peer reviewed.

\section{REFERENCES}

1 Heather N, Segal G, eds. Addiction \& choice. Oxford: Oxford University Press, 2017.

2 Heyman GM. Addiction. Cambridge, MA: Harvard University Press, 2009.

3 Volkow ND, Koob GF, McLellan AT. Neurobiologic advances from the brain disease model of addiction. N Engl J Med 2016;374:363-71.

4 Levine HG. The discovery of addiction. Changing conceptions of habitual drunkenness in America. J Stud Alcohol 1978;39:143-74.

5 Nicholls J. The politics of alcohol. Manchester: Manchester University Press, 2009.

6 Porter R. The drinking man's disease: the 'pre-history' of alcoholism in Georgian Britain. Br J Addict 1985;80:385-96.

7 Reinarman C. Addiction as accomplishment: the discursive construction of disease. Addict Res Theory 2005;13:307-20.

8 Reith G. Addiction and consumption. London: Routledge, 2018.

9 Schneider JW. Deviant drinking as disease: alcoholism as a social accomplishment. Social Problems 1978;25:361-72.

10 Valverde M. Diseases of the will. Cambridge: Cambridge University Press, 1998.

11 Rush B. An inquiry into the effects of ardent spirits upon the human body and mind. New Brunswick, NJ: A. Blauvelt, 1805.

12 Rush B. Medical Inquiries and Observations upon Diseases of the Mind. Philadelphia, PA: Kimber \& Richardson, 1812:266.

13 Leshner Al. Addiction is a brain disease, and it matters. Science 1997;278:45-7.

14 Fraser S, Pienaar K, Dilkes-Frayne E, et al. Addiction stigma and the biopolitics of liberal modernity: a qualitative analysis. Int J Drug Policy 2017;44:192-201. 
15 Substance Abuse and Mental Health Services Administration, Office of Applied Studies. The NSDUH Report: Substance Use and Dependence Following Initiation of Alcohol or Illicit Drug Use. Rockville, MD, 2008.

16 Acker CJ. Creating the American Junkie. Baltimore, MD: Johns Hopkins University Press, 2002.

17 Weinberg D. Of others inside. Temple, Philadelphia, PA, 2005.

18 Campbell ND. Discovering addiction. Ann Arbor, MI: University of Michigan Press, 2007.

19 Lewis M. The biology of desire. New York: Public Affairs, 2015.

20 Courtwright DT. The NIDA brain disease paradigm: History, resistance and spinoffs. BioSocieties 2010:5:137-47.

21 Lewis M. Brain change in addiction as learning, not disease. N Eng/ J Med 2018;379:1551-60.

22 Robinson TE, Berridge KC. Addiction. Annual Review of Psychology 2003;54:25-53.

23 Goldstein RZ, Volkow ND. Dysfunction of the prefrontal cortex in addiction: neuroimaging findings and clinical implications. Nat Rev Neurosci 2011;12:652-69.

24 Alasuutari P. Desire and craving. Stony Brook, NY: SUNY Press, 1992.

25 Hochschild AR. The managed heart. 3rd edn. Berkeley: University of California Press, 2012.

26 Turner RH. The real self: from institution to impulse. AJS 1976;81:989-1016.

27 In: Granfield R, Reinarman C, eds. Expanding addiction. London: Routledge, 2015.

28 Netherland J, ed. Critical perspectives on addiction. Bingley, UK: Emerald, 2012.

29 Satel S, Scott O. Brainwashed. New York, NY: Basic Books, 2013.

30 Mill JS. On liberty. New York, NY: Cosimo, Inc 2005, 1859.

31 Bennett F, Julian S. A liberal account of addiction. Philosophy, Psychiatry, \& Psychology 2010;17:1-22.

32 Szasz T. Ceremonial chemistry, revised edition. Syracuse, NY: Syracuse University Press, 2003.

33 Duster T. The legislation of morality. New York: The Free Press, 1970.

34 Hughes K. Migrating identities: the relational constitution of drug use and addiction. Sociol Health IIIn 2007;29:673-91.

35 Lindesmith AR. The drug addict as a psychopath. American Sociological Review 1940;5:914-20.

36 Room R. Alcohol and ethnography: a case of problem deflation? Current Anthropology 1984;25:169-78.

37 Weinberg D. Post-humanism, addiction and the loss of self-control: reflections on the missing core in addiction science. Int J Drug Policy 2013;24:173-81.

38 Weinberg D. Sociological perspectives on addiction. Sociology Compass 2011;5:298-310.

39 Becker GS, Murphy KM. A theory of rational addiction. Journal of Political Economy 1988;96:675-700.

40 Orphanides A, Zervos D. Rational addiction with learning and regret. Journal of Political Economy 1995;103(no. 4):739-58.

41 Ainslie G. Picoeconomics. Cambridge: Cambridge University Press, 1992.

42 Elster J, ed. Addiction. New York: Russell Sage Foundation, 1999.

43 Rogeberg 0. Taking absurd theories seriously: economics and the case of rational addiction theories* ${ }^{*}$. Philosophy of Science 2004;71:263-85.
44 Weinberg D. "Out there": the ecology of addiction in drug abuse treatment discourse. Social Problems 2000;47:606-21.

45 Pickard H. Responsibility without blame for addiction. Neuroethics 2017;10:169-80.

46 Lewis M. A graded approach to "disease" - help or hindrance? reply to berridge. Neuroethics 2017;10:35-7.

47 Lewis M. Yes, Precision is a Good thing. Reply to Flanagan. Neuroethics 2017;10:99-101.

48 Mills. On Liberty: 17.

49 Greco M. Illness as a work of thought. London: Routledge, 1998.

50 Rosenberg CE. Explaining epidemics. Cambridge: Cambridge University Press, 1992.

51 Latour B. How to talk about the body? The normative dimensions of science studies. Body \& Society 2004;29:205205.

52 Lewis M. Choice isn't simple. Reply to Pickard. Neuroethics 2017;10:181-3.

53 Berridge KC. Taste reactivity: measuring hedonic impact in infants and animals. Neuroscience and Biobehavioral Reviews 2000;24:173-98.

54 Merleau-Ponty M. The phenomenology of perception. New York: Routledge and Kegan Paul, 1962:183.

55 Bourdieu P. Practical reason. Stanford, CA: Stanford University Press, 1998:78-9.

56 Bourdieu P. Practical reason:8.

57 Silva EB. Unity and fragmentation of the habitus. The Sociological Review 2016;64:166-83.

58 Wacquant L. A concise genealogy and anatomy of habitus. The Sociological Review 2016;64:64-72.

59 Winick C. Maturing out of narcotic addiction. Bulletin on Narcotics 1962;14(5):1-7.

60 ROBINS LEEN. Vietnam veterans' rapid recovery from heroin addiction: a fluke or normal expectation? Addiction 1993;88:1041-54.

61 Waldorf $D$. Natural recovery from addiction: some social-psychological processes of untreated recovery. Journal of Drug Issues 1983;13:237-80.

62 Biernacki P. Pathways from heroin addiction. Philadelphia, PA: Temple University Press, 1986.

63 Waldorf D, Reinarman C, Murphy S. Cocaine changes. Philadelphia, PA: Temple University Press, 1991:10.

64 Ainslie G. Intertemporal bargaining in habit. Neuroethics 2017;10:143-53.

65 Duff C. The pleasure in context. Int J Drug Policy 2008;19:384-92.

66 Fraser S, Moore D, Keane H, et al. Habits. London: Palgrave, 2014.

67 Garriott W, Raikhel E. Addiction in the making. Annual Review of Anthropology 2015:44:477-91.

68 Källmén H, Gustafson R. Alcohol and disinhibition. European Addiction Research 1998:4:150-62.

69 MacAndrew C, Edgerton R. Drunken comportment. Clinton Corners, NY: Percheron Press, 2003.

70 Baumeister RF. Ego depletion and self-control failure: an energy model of the self's executive function. Self and Identity 2002;1:129-36.

71 Lewis M. Addiction and the Brain: development, not disease. Neuroethics 2017; 10:7-18.

72 Geertz C. The interpretation of cultures. New York, NY: Basic Books, 1973. 